\title{
The In-situ Analysis of Precipitates in Some Mg-Rare Earth Alloys
}

\author{
G.W. Lorimer, G. Cliff and P. Apps \\ Materials Science Centre, School of Materials, University of Manchester, Grosvenor Street, \\ Manchester, M1 7HS, UK
}

High strength magnesium casting alloys based on the Mg-Y-Nd system are the basis of the successful commercial alloy WE43 (Mg-4wt\%Y-2.25wt\%Nd-1wt\%HRE-0.6wt\%Zr) [1]. The alloy is precipitation hardened and exhibits a complex precipitation sequence[2]: $\operatorname{Mg}($ SSSS $) \rightarrow \beta^{\prime}, \rightarrow \beta$ ' $\rightarrow \beta_{1} \rightarrow \beta$. For cost reasons, the heavy rare earth additions (HRE) are usually added in the form of a 'Misch Metal' which contains a number of rare earths and reflects the geological origin of the HRE ore. Work in Russia[3] has indicated that the additions of single rare earth elements can result in enhanced tensile properties. The current research was undertaken to investigate the effect of additions of Gd and Dy. Four alloys were investigated: WE43, WN42 (Mg$4 \% \mathrm{Y}-2.25 \% \mathrm{Nd}-0.6 \% \mathrm{Zr}$ ), DN72 (Mg-7\%Dy-2.25\%Nd-0.6\%Zr) and GN72 (Mg-7\%Gd-2.25\%Nd$0.6 \% \mathrm{Zr})$.

The three alloys were sand-cast and solution treated (for $8 \mathrm{hrs}$ at $525^{\circ} \mathrm{C}$ ) by Magnesium Elektron (MEL). Samples for TEM analysis were electropolished and, immediately prior to analysis, were given a thirty minute "ion beam wipe" in a Gatan PIPS ion beam polisher with a gun potential of $3.7 \mathrm{kV}$ and beam current of the order of $10 \mu \mathrm{A}$. Examination was carried out in a Philips CM20 TEM operating at $200 \mathrm{kV}$.

Quantitative energy dispersive spectroscopy of thin foils was carried out following the method developed by Cliff and Lorimer [4]. A variety of theoretical models for $\mathrm{k}_{\mathrm{AB}}$ factors are available, however, these were found to be unreliable when dealing with the rare earth elements. For this study, experimental $\mathrm{k}_{\mathrm{AB}}$ values were determined for yttrium and the rare earth elements using the matrices of the solution treated alloys as TEM standards. Bulk electron probe microanalysis (EPMA) showed a uniform composition in the matrix of the solution treated alloys, and good agreement with the mass spectroscopy analyses carried out during alloy production. $\mathrm{k}_{\mathrm{AB}}$ factors were determined from subsequent EDX analyses of these samples in the TEM. The $\mathrm{k}_{\mathrm{AB}}$ factors determined experimentally were: $\mathrm{k}_{\mathrm{MgNd}}(\mathrm{Nd} \mathrm{L})=3.5, \mathrm{k}_{\mathrm{MgY}}(\mathrm{Y} \mathrm{K})=2.1, \mathrm{k}_{\mathrm{MgDy}}(\mathrm{Dy} \mathrm{L})=3.6$ and $\mathrm{k}_{\mathrm{MgGd}}(\mathrm{Gd} \mathrm{L})=3.5$.

In Fig. 1 results are presented for the examination of the $\beta_{1}$ precipitates which were formed in the four alloys after solution treatment at $525^{\circ} \mathrm{C}$ for $8 \mathrm{~h}$, hot water quenching and ageing at $300{ }^{\circ} \mathrm{C}$ for 30 minutes. A typical microstructure showing the $\beta_{1}$ precipitates in alloy GN72 is shown in Fig. 1(a). Electron diffraction indicted that in all alloys the $\beta_{1}$ precipitates had the same FCC lattice with a $\sim 0.74 \mathrm{~nm}$. The activated volume for the analyses of the precipitates included the surrounding matrix and results are presented using the extrapolation technique described by Lorimer et al [5].

The results in Fig.1(b)-(e) show that in alloy GN72 the Gd concentration in the $\beta_{1}$ precipitates is higher than Nd while in alloys DN72, WN42 and WE43 the $\beta_{1}$ precipitates are rich in Nd. 


\section{References}

[1] J.F. King J.F.in Adv. Mat. Tech. Inter.. Ed.G. B Brook Ed. (1990) 12.

[2] L. L.Rokhlin, in Advanced Light Alloys and Composites, Proceedings of NATO Advanced

Study Institute. Kluwer, (1998) 443.

[3] J. F. Nie and B.C. Muddle, Acta Mat. 48 (2000) 1691.

[4] G. Cliff and G. W. Lorimer, J.Microsc. 103 (1975) 203.

[5] G.W. Lorimer et al. in Analytical Electron Microscopy. Eds. Williams DB, Joy DC. San Francisco Press, (1984.)153.

[6] This work was supported by the EPSRC and Magnesium Elektron Ltd.
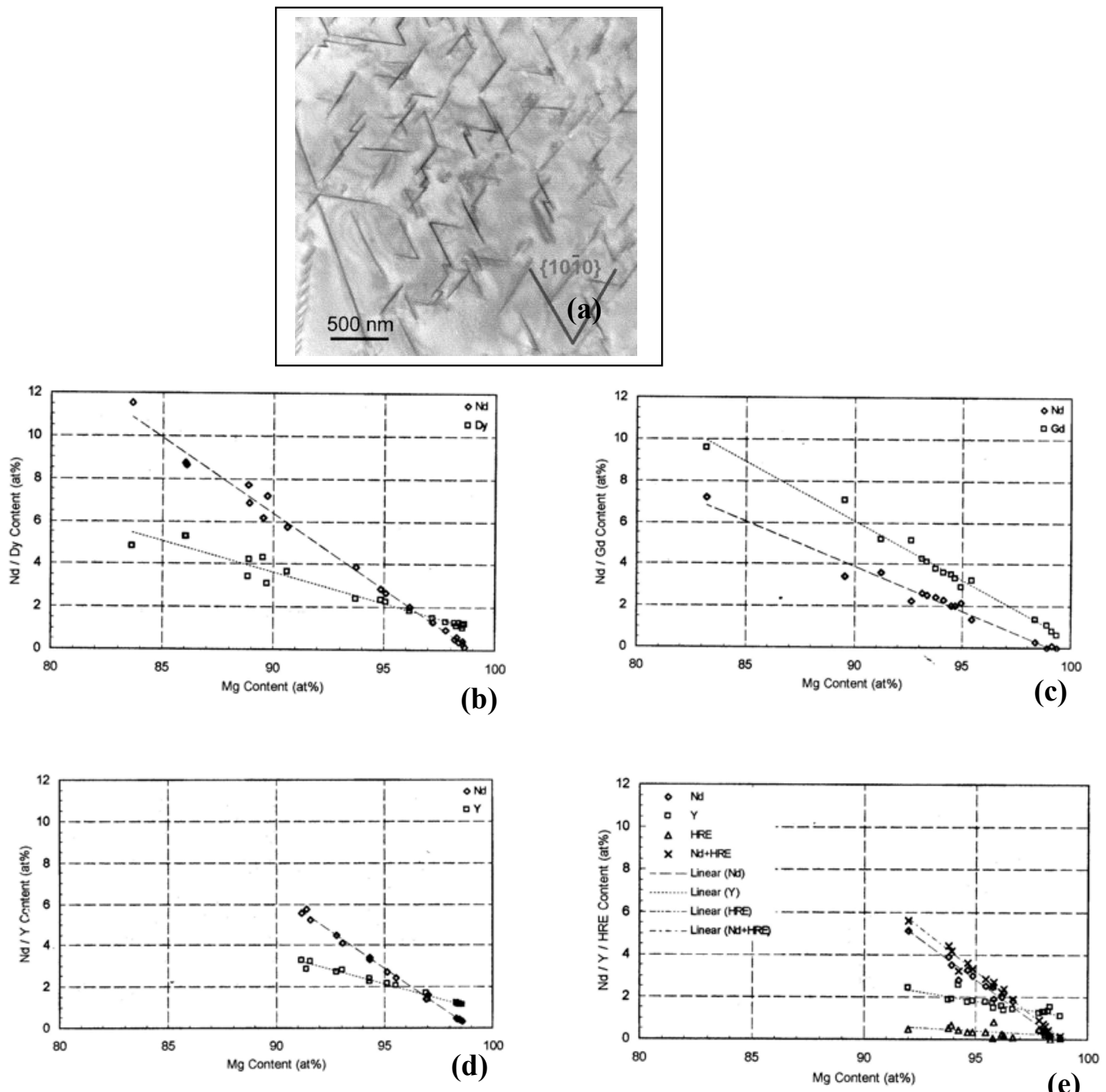

Fig.1 (a) Microstructure of GN72 viewed along [0001 $]_{\text {Mg }}$ showing plate-shaped precipitates of $\beta_{1}$ on the prism planes. In-situ analyses of $\beta_{1}$ precipitates in alloys (b) DN 72, (c) GD 72 , (d) WN 42 and (e) WE 43. 